\title{
BEHAVIOUR FACTOR EVALUATION OF SHEATHED COLD-FORMED STEEL STRUCTURES
}

\author{
Luigi Fiorino ${ }^{1}$, Ornella Iuorio ${ }^{2, *}$ and Raffaele Landolfo ${ }^{2}$ \\ ${ }^{I}$ Department of Structural Engineering, Faculty of Engineering, University of Naples Federico II \\ ${ }^{2}$ Department of Constructions and Mathematical Methods in Architecture, Faculty of Architecture, \\ University of Naples Federico II, Naples, Italy \\ *(Corresponding author: E-mail: ornella.iuorio@unina.it)
}

Received: 3 November 2011; Revised: 25 June 2012; Accepted: 29 June 2012

\begin{abstract}
The seismic behaviour of sheathed cold-formed steel (SCFS) structures is characterized by the lateral response of shear walls. Basically, if cold-formed steel (CFS) structures are designed according to the "sheathing-design" methodology, then the seismic behavior of shear walls is strongly influenced by the sheathing-to-frame connections response, characterized by a remarkable nonlinear response and a strong pinching of hysteresis loops. In this paper the results of an extensive parametric non linear dynamic analysis, carried out on one story buildings by means of incremental dynamic analysis (IDA), using an ad hoc model of the hysteresis response of SCFS shear walls, are presented. An extended number of wall configurations has been considered investigating several parameters such as sheathing panel typology, wall geometry, external screw spacing, seismic weight and soil type. Based on IDA results, three behavior factors have been defined, which take into account overstrength, ductility and both overstrength and ductility, respectively.
\end{abstract}

Keywords: Behavior factor, Cold formed steel, Parametric study, Seismic design, Sheathing-Braced structures, Seismic dynamic analysis, Seismic force modification factor

\section{INTRODUCTION}

The seismic behaviour of cold-formed steel (CFS) structures sheathed with panels is influenced by the response of shear walls, which are characterized by a highly non-linear structural response. In order to assess the seismic performance of sheathed cold-formed steel (SCFS) structures, some experimental and/or numerical research programs have been carried out on different wall configurations. On the basis of results provided by tests and analysis, different seismic design parameters, such as behaviour factor ( $q$, using the European terminology) or seismic force modification factor ( $R$, according to the USA terminology) (Fülöp and Dubina [1-2], Boudreault et al. [3]) and interstory drift limits (Kawai et al. [4], Boudreault et al. [3], Dubina [5]) have been identified, and interesting seismic design methods have been proposed (Kawai et al. [4]). In addition, other studies, focused on the dynamic characteristics of this type of structures (Kawai et al. [4], Gad et al. [6], Dubina [5]), have identified typical values of vibration period and damping ratio.

According to current standards, the seismic design is widely performed by means of force-based linear approaches, in which the structural inelastic response and overstrength are taken into account by reducing the actions produced by earthquakes through seismic force reduction factors, called behavior factor hereafter. In the case of SCFS structural systems, specific studies on the evaluation of behavior factor are needed to taking into account the peculiarity of their dynamic response, characterized by low natural period (generally from 0.1 to $0.3 s$ ) and highly non-linear pinched force-displacement response. An literature overview on proposed behavior factor is given in Section 2. Nowadays, two main approaches devoted to seismic force reduction factor assessment are available: experimental and numerical. Due to the limited sample of shear wall configurations on which a experimental campaign can be carried out, the evaluation of behavior factor in this research has been mainly performed by a very extensive parametric non-linear time-history dynamic analyses, which are described in Sections 3 and 4. The parametric analysis has been developed through the incremental non-linear dynamic analysis (IDA), in which for the definition 
of the two main parameters related to the structural performance and earthquake record magnitude, the inter-story drift and the adimensionalized elastic spectral acceleration corresponding to the first mode period of the structure have been assumed, respectively. In particular, the IDA has been performed on one-story buildings with and without attic, representative of a large range of solutions of stick-built constructions and considering seismic inputs selected in such a way that they could cover all the soil typologies classified by Eurocode 8 (CEN [8]), for a total number of 529200 single non-linear dynamic analysis. On the basis of IDA results, an evaluation of behavior factors has been carried out (Section 5) by following two different approaches called "classical" and "multi-performance". In particular, for the "classic" approach the evaluation of the behavior factor follows the common assumptions made in the current seismic codes, i.e. it is based on seismic demands required by records representative of $10 \% / 50$ earthquakes, by relating this hazard level to the life safety structural performance. In the "multi-performance" approach, instead, different behavior factors are defined by relating they to different seismic performance levels, in such a way to obtain a "multi-performance" seismic design and to give the possibility to achieve an "enhanced objective" (FEMA [8]).

\section{OVERVIEW ON SEISMIC FORCE REDUCTION FACTORS}

As far as the definition of behaviour factor is concerned, monotonic and cyclic tests on walls sheathed with trapezoidal steel sheets or oriented strand board (OSB) panels with or without openings were carried out by Fülöp \& Dubina [1]. On the basis of this experimental results they developed a numerical model and performed incremental dynamic analysis. Therefore, the Authors define three different behaviour factors (Fülöp and Dubina [2]): $q_{1}$, corresponding to the overstrength, $q_{2}$ corresponding to the ductility, and $q_{3}=q_{1} q_{2}$, which takes into account both effects. The behaviour factor $q_{1}$ ranges from 2.2 to $2.6, q_{2}$ ranges from 1.4 to 1.6 and $q_{3}$ is in the range 3.6 through 3.7. In particular, in the case of walls sheathed with OSB panels and without openings the Authors found the following average behaviour factors: $q_{1}=2.7, q_{2}=1.4$ and $q_{3}=3.7$. Boudreault et al. [3] evaluated the seismic force modification factors $(R)$ due to the ductility $\left(R_{d}\right)$ and overstrength $\left(R_{o}\right)$ as defined by the National Building Code of Canada NBCC [9]. The proposed values $R_{d}=2.5, R_{o}=1.7$, and $R=R_{o} R_{d}=4.3$ were obtained by analyzing the results of monotonic and cyclic tests on different configurations of walls sheathed with plywood and OSB panels (Branston et al. [10]; Blais [11]; Rokas [12]). The values obtained on experimental basis were verified through the results of non-linear dynamic analysis (time-history) carried out on two representative buildings (Boudreault et al. [3]). Values of seismic force reduction factor ( $R$-factor) for CFS buildings are also provided in a number of Codes, as the ASCE / SEI 7-10 [13], and the FEMA P750 [8]. In particular, for shear walls sheathed with wood panels or steel sheets, values of R-factor equal to 7 and 6.5 are provided by ASCE/SEI 7-10 and Fema P750, respectively. In the case of other sheathing typologies, the provided values are 2.5 and 2 for ASCE/SEI 7-10 and FEMA P750, respectively. All the values defined by Authors and codes are summarized in Table 1.

Table 1. Behaviour Factors

\begin{tabular}{ccccc}
\hline Author & Type of sheathing & $q_{1}$ & $q_{2}$ & $q_{3}$ \\
\hline Fülöp \& Dubina & OSB (without openings) & 2.7 & 1.4 & 3.7 \\
\hline Boudreault et al. & Plywood or OSB & 1.7 & 2.5 & 4.3 \\
\hline ASCE & Wood or steel & - & - & 2.5 \\
\hline FEMA P 750 & Wood or steel & - & - & 6.5 \\
\hline FEMA P 750 & Other materials & - & - & 2 \\
\hline
\end{tabular}




\section{MONOTONIC RESPONSE EVALUATION}

\subsection{Model for Monotonic Response Prediction}

In this paper the analytical-numerical model proposed by the authors (Landolfo et al [14]), that allows the evaluation of the monotonic lateral response of a SCFS shear wall, has been used. The method is based on the most common assumptions made for other available approaches, such as full anchorage between frame and foundation or other stories and sheathing-to-frame interaction characterized by a "rigid body" behaviour. The model allows the evaluation of each wall deflection contribution, from which the total wall deflection can be obtained by adding the deformation due to bending $\left(d_{F}\right)$, sheathing fasteners $\left(d_{F-S}\right)$, sheathing panels $\left(d_{S}\right)$, and anchorages $\left(d_{F-F}\right): d=d_{F}+d_{F-S}+$ $d_{S}+d_{F-F}$.
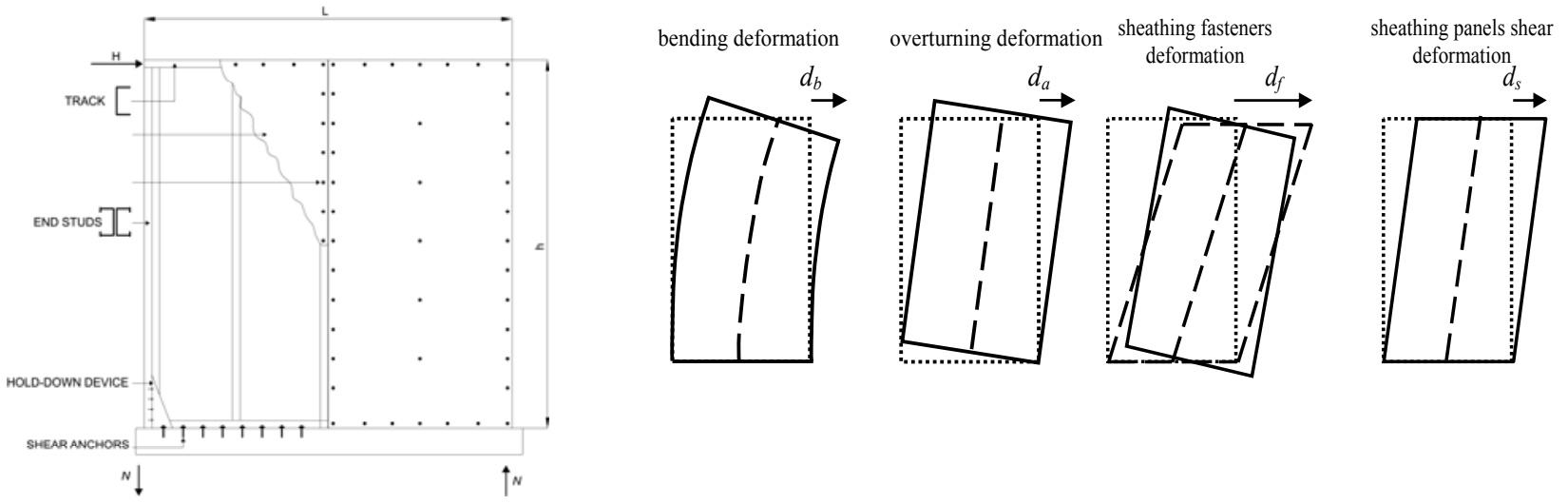

Figure 1. Wall Components and Deformation Contributions

The model has been calibrated on the basis of monotonic tests on full scale specimens (Landolfo et al. [15]) carried out on CFS shear walls sheathed with OSB and gypsum board (GWB) and tests performed on sheathing connections (Iuorio, [16]) that are nominally identical to that used for the walls. Further details about hypothesis and applicability of the model can be found in Fiorino et al. [17].

\subsection{Parametric Study}

In order to study the behaviour of different wall configurations, the model has been applied to simulate the monotonic response of 72 different wall configurations. All the walls are made of $100 \times 50 \times 10 \mathrm{~mm}$ (outside-to-outside web depth $\times$ outside-to-outside flange size $\times$ outside-to-outside lip size) lipped channel studs, spaced at $600 \mathrm{~mm}$ and sheathed with GWB panels on both sides $(\mathrm{G}+\mathrm{G})$ or GWB on one side and OSB panels on the other side $(\mathrm{G}+\mathrm{O})$. The thicknesses of $\mathrm{GWB}$ and OSB panels are $12.5 \mathrm{~mm}$ and $9.0 \mathrm{~mm}$, respectively. For connecting sheathing panels and frame $4.2 \times 25 \mathrm{~mm}$ (diameter $\times$ length) flat head self drilling screws have been considered for OSB and $3.5 \times 25 \mathrm{~mm}$ bugle head for GWB. The fasteners have spacing equal to $300 \mathrm{~mm}$ in the field, while different external screw spacing have been investigated. Hold down devices type Simpson Strong-Tie [18] and chemical anchorage (type HIT-RE 500 with HIS-N 8.8 by Hilti [19]) have been considered at each end of the wall, while mechanical shear anchors (type HST M8 by Hilti) have been hypothesized. Sheathing panel typology, wall geometry (height $h$ and length $l$ ) and external screw spacing $(s)$ have been varied as summarized in Table 2. For each wall configuration obtained by combining the parameters given in Table 1 , the stud thickness $\left(t_{F}\right)$ and hold-down device typology have been selected in such a way to promote the sheathing fasteners collapse, as shown in Table 2 . The monotonic response of the walls has been obtained by considering a shear modulus $(G)$ 
of $1400 \mathrm{MPa}$ for OSB panels and $750 \mathrm{MPa}$ for GWB panels. In addition, a Young modulus $(E)$ for the steel equal to $200000 \mathrm{MPa}$ has been adopted, while the assumed values of hold down device axial stiffness $\left(K_{a}\right)$ are given in Table 3 .

Table 2. Variables Assumed in the Parametric Study

\begin{tabular}{ll}
\hline Sheathing panel typology & $\mathrm{GWB}+\mathrm{GWB}(\mathrm{G}+\mathrm{G}), \mathrm{GWB}+\mathrm{OSB}(\mathrm{G}+\mathrm{O})$ \\
\hline Wall height $(h)[\mathrm{mm}]$ & $2400,2700,3000$ \\
\hline Wall length $(l)[\mathrm{mm}]$ & $1200,2400,9600$ \\
\hline External screw spacing $(s)[\mathrm{mm}]$ & $50,75,100,150$ \\
\hline
\end{tabular}

Table 3. Selected Stud Thicknesses and Hold Down Devices

\begin{tabular}{llll}
\hline $\begin{array}{l}\text { Wall typology } \\
{[s \text { and } h \text { in mm }]}\end{array}$ & Hold down & $\begin{array}{l}\text { stud }\left(t_{F}\right) \\
{[\mathrm{mm}]}\end{array}$ & $\begin{array}{l}K_{a} \\
{[\mathrm{kN} / \mathrm{mm}]}\end{array}$ \\
\hline $\begin{array}{l}\mathrm{G}+\mathrm{G} ; s=75,100,150 \\
\mathrm{G}+\mathrm{O} ; s=150\end{array}$ & $\mathrm{~S} / \mathrm{HD} 8 \mathrm{~B}$ & 1.0 & 28 \\
\hline $\begin{array}{l}\mathrm{G}+\mathrm{O} ; s=75 ; h=2400,2700 \\
\mathrm{G}+\mathrm{O} ; s=100 ; h=2400\end{array}$ & S/HD 8B & 1.5 & 28 \\
\hline $\begin{array}{l}\mathrm{G}+\mathrm{G} ; s=50 \\
\mathrm{G}+\mathrm{O} ; s=100 ; h=2700,3000\end{array}$ & $\mathrm{~S} / \mathrm{HD} 10 \mathrm{~B}$ & 1.0 & 27 \\
\hline $\mathrm{G}+\mathrm{O} ; s=50 ; h=2400$ & & & \\
\hline $\mathrm{G}+\mathrm{O} ; s=50 ; h=2700,3000$ & $\mathrm{~S} / \mathrm{HD} 10 \mathrm{~B}$ & 1.5 & 27 \\
\hline $\mathrm{G}+\mathrm{O} ; s=75 ; h=3000$ & S/HD 15B & 1.5 & 31 \\
\hline
\end{tabular}

\section{EVALUATION OF CYCLIC RESPONSE}

\subsection{Cyclic Response Modelling}

In this study an upgraded version of the cyclic model proposed in Della Corte et al [20], which takes into account the strength degradation, has been used. According to this approach, in order to model the cycle lateral response of shear walls in terms of horizontal force $(H)$ vs. lateral deflection (d), the definition of three limit curves, together with the definition of transition and strength degradation laws are needed (Figure 2). The first curve (monotonic curve) represents the monotonic response, while the other curves represent the upper bound cyclic (UBC) curve and the lower bound cyclic (LBC) curve to all possible $H-d$ values obtained in the cyclic response. For each curve a 6 independent parameters Richard-Abbott type law is assumed, with the following parameters for the monotonic curve: $K_{0}$ is the initial stiffness; $H_{0}$ is the intersection between the hardening line and the $d=0$ axis; $K_{h}$ is the slope of the hardening line; $n$ is the shape parameter regulating the sharpness of transition from the elastic to the plastic behaviour; $d_{p}$ is the peak deflection; $K_{d}$ is the post-peak stiffness; $d_{u}$ is the conventional ultimate deflection corresponding to a load equal to 0.80 time the peak horizontal force $\left(H_{p}\right)$ on the post-peak branch of response curve (dependent parameter). The same parameters are needed for the definition of UBC curve $\left(K_{0 U}, H_{0 U}, K_{h U}, n_{U}, d_{p U}, K_{d U}, d_{u U}\right)$ and LBC curve $\left(K_{0 L}, H_{0 L}, K_{h L}, n_{L}, d_{p L}, K_{d L}, d_{u L}\right)$.

The model assumes that the UBC and LBC curves can be derived from the monotonic response curve on the basis of these assumptions:

$X_{U}=U_{X} \cdot X$

$X_{L}=L_{X} \cdot X$ 
where $X, X_{U}$, and $X_{L}$ represent the generic independent parameters defining the monotonic, UBC and LBC curve, respectively (i.e. $X=K_{0}, X_{U}=K_{0 U}$ and $X_{L}=K_{0 L}$ ); $U_{X}$ and $L_{X}$ are the relevant constant (i.e. $U_{X}=U_{K 0}$ and $L_{X}=L_{K 0}$, thus $K_{0 U}=U_{K 0} K_{0}$ and $K_{0 L}=L_{K 0} K_{0}$ ).

Other assumption of the proposed methodology is that the generic point of a cyclic loading branch belongs to a Richard-Abbott type curve (transition curve), whose the relevant independent parameters $K_{0 t}, H_{0 t}, K_{h t}, n_{p t}, d_{p t}, K_{d t}$ are given by the linear convex combination of analogous parameters of the LBC and UBC curves:

$X_{t}=X_{L}+\left(X_{U}-X_{L}\right) t$

where $X_{t}$ represents the generic independent parameter defining the transition curve (i.e. $X_{t}=K_{0 t}$, thus $K_{0 t}=K_{0 L}+\left(K_{0 U}-K_{0 L}\right) t$ ), and $t$ defines the transition law from the LBC to the UBC curve:

$t=\left[\frac{\left[d /\left(\lambda\left(\left|d_{0}\right|+d_{\max }\right)\right)\right]}{\left[d /\left(\lambda\left(\left|d_{0}\right|+d_{\max }\right)\right)\right]^{t_{1}}+1}\right]^{t_{2}}$ with $0 \leq t \leq 1$

in which $d_{0}$ is the deflection corresponding to the initial point of the current excursion and $d_{\max }$ is the maximum deflection value reached in all previous loading history in the direction to be described. Therefore, $t$ can be defined by assigning $t_{1}, t_{2}$ and $\lambda$.

The strength degradation is taken into account following the methodology proposed by Park and Ang (Park [21]):

$H_{0, \text { red }}=H_{0}\left(1-D_{F}\right)$

where $H_{0, \text { red }}$ is the reduced value of $H_{0}$ in the current cycle excursion and $D_{F}$ represent the parameter accounting for the strength reduction.

As results, the proposed model depends on 22 independent parameters $\left(K_{0}, H_{0}, K_{h}, n, d_{p}, K_{d}, U_{K 0}\right.$, $\left.U_{H 0}, U_{K h}, U_{n}, U_{d p}, U_{K d}, L_{K 0}, L_{H 0}, L_{K h}, L_{n}, L_{d p}, L_{K d}, t_{1}, t_{2}, \lambda, D_{F}\right)$.

The calibration of the parameters describing the whole cyclic response has been carried out on the basis of available results of experimental monotonic and cyclic full scale tests (Landolfo et al. [15]). The values of the monotonic curve parameters $\left(K_{0}, H_{0}, K_{h}, n, d_{p}, K_{d}\right)$ have been obtained in such a way that this curve matches the experimental monotonic response curve, while the UBC curve parameters $\left(U_{K 0}, U_{H 0}, U_{K h}, U_{n}, U_{d p}, U_{K d}\right)$ have been defined in order to match the envelope of the experimental cyclic response curve. Finally, the values of the LBC curve $\left(L_{K 0}, L_{H 0}, L_{K h}, L_{n}, L_{d p}, L_{K d}\right)$, transition $\left(t_{1}, t_{2}\right.$, and $\left.\lambda\right)$ and strength degradation $\left(D_{F}\right)$ parameters have been defined in such a way that the numerical cyclic response would be as much as possible similar to the experimental cyclic response in terms of $H-d$ curve and dissipated energy. The parameters values obtained as result of calibration are given in Table 4, while the comparison in terms of response is shown in Figure 2. 


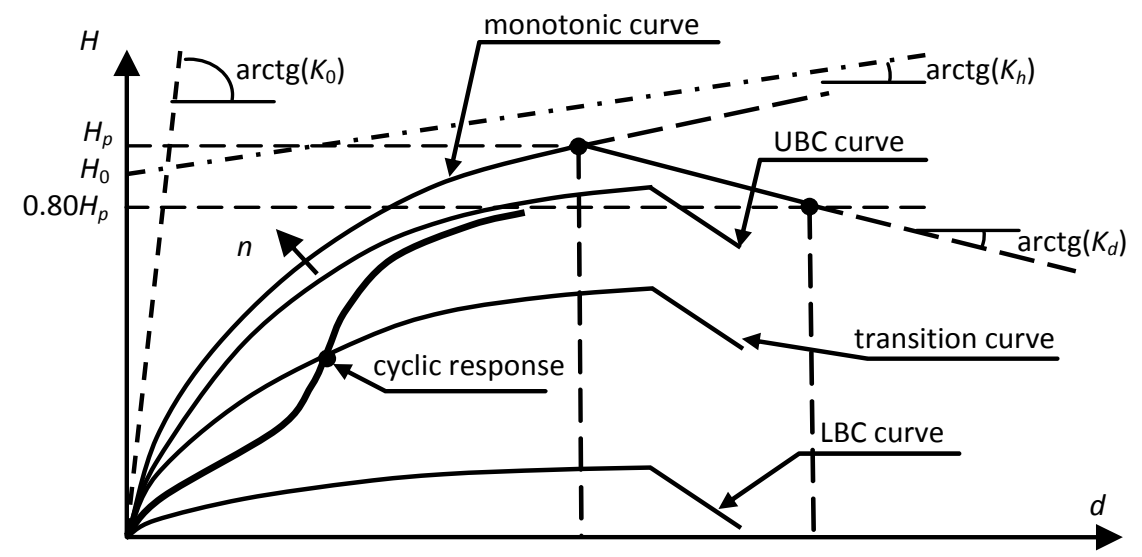

Figure 2. Model of the Cycle Lateral Response of SCFS Shear Walls

Table 4. Parameters Defining the Cyclic Response, as Result of Calibration

\begin{tabular}{lllllll}
\hline Monotonic curve parameters & $K_{0}=6.05 \mathrm{kN} / \mathrm{mm} / \mathrm{m}$, & $H_{0}=24 \mathrm{kN} / \mathrm{m}$, & $K_{h}=0.03$, & $n=0.78$, & $d_{p}=24 \mathrm{~mm}$, & $K_{d}=-0.15$ \\
\hline UBC curve parameters & $U_{K 0}=0.67$, & $U_{H 0}=0.88$, & $U_{K h}=0.0$, & $U_{n}=1.0$, & $U_{d p}=1.5$, & $U_{K d}=7.0$ \\
\hline LBC curve parameters & $L_{K 0}=0.67$, & $L_{H 0}=0.01$, & $L_{K h}=0.0$, & $L_{n}=1.0$, & $L_{d p}=1.5$, & $L_{K d}=1.0$ \\
\hline Transition parameters & $t_{l}=12$, & $t_{2}=0.8$, & $\lambda=0.9$ & & & \\
\hline Strength degradation parameter & $D_{F}=0.10$ & & & & \\
\hline
\end{tabular}

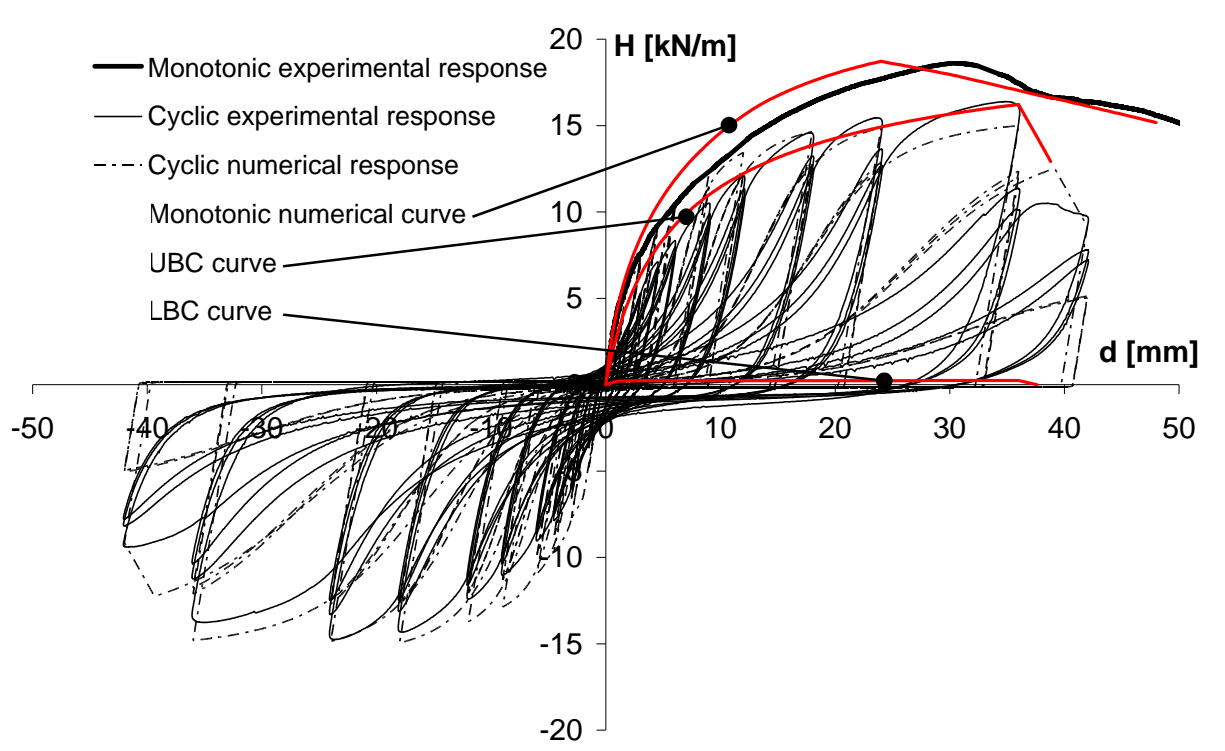

Figure 3. Calibration Results in Terms of Force vs. Displacement Response

\subsection{Building Case Study}

One-story buildings have been considered as case studies. They refer to stick built constructions in which both floors and walls are realized with CFS framing sheathed with structural panels. In particular, in order to obtain a large range of solutions, a schematic plan has been considered with wall length $(L)$ variable between 3 and $7 \mathrm{~m}$ (Figure 4) and lengths of full height (resisting) wall segment $(l)$ in the range $l=0.4 L$ through $l=0.7 \mathrm{~L}$. 

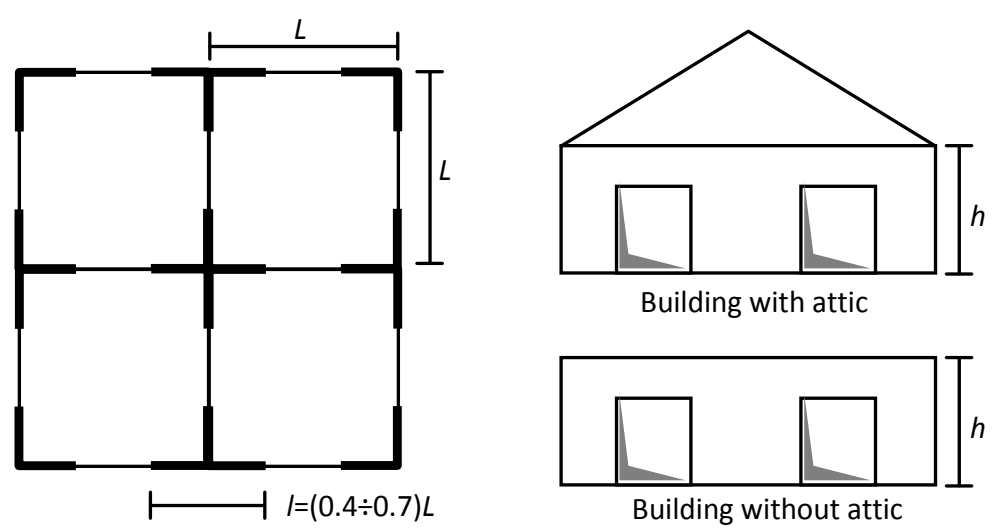

Figure 4. Case Study: The Schematic Stick Built Construction

\subsection{Actions}

Unit weights ranging from 0.4 to $1.5 \mathrm{kN} / \mathrm{m}^{2}$ and from 0.3 to $1.2 \mathrm{kN} / \mathrm{m}^{2}$ have been considered for floors and walls, respectively (Table 5). Moreover, the building has been considered without and with attic. In the first case, a variable live load of $2.0 \mathrm{kN} / \mathrm{m}^{2}$ has been considered and, in the latter case, a snow variable load ranging from 0.60 to $1.20 \mathrm{kN} / \mathrm{m}^{2}$ has been added. The seismic weights have been defined according to the following relationship:

$\Sigma G_{K i}+\Sigma_{j}\left(0,3 \cdot Q_{K j}\right)$

where $G_{k i}$ are the characteristic value of permanent actions and $Q_{k i}$ are the variable loads. With this conditions, a seismic weight for unit wall length ranging between 2 and $38 \mathrm{kN} / \mathrm{m}$ has been obtained. Therefore, 7 seismic weights per unit wall length have been considered $(10,15,20,25,30,35$ and 40 $\mathrm{kN} / \mathrm{m}$ ) and have been applied to the 72 wall configurations defined previously in the parametric study in such a way to obtain a total number of $7 \times 72=504$ cases.

Table 5. Unit Weights

\begin{tabular}{ll}
\hline Floor and roof & \\
\hline Steel members & $0.08 \div 0.25 \mathrm{kN} / \mathrm{m}^{2}$ \\
\hline OSB panels & $0.10 \div 0.15 \mathrm{kN} / \mathrm{m}^{2}$ \\
\hline GWB panels & $0.00 \div 0.10 \mathrm{kN} / \mathrm{m}^{2}$ \\
\hline Insulation & $0.02 \div 0.30 \mathrm{kN} / \mathrm{m}^{2}$ \\
\hline Floor finishing & $0.10 \div 0.40 \mathrm{kN} / \mathrm{m}^{2}$ \\
\hline False ceiling & $0.10 \div 0.30 \mathrm{kN} / \mathrm{m}^{2}$ \\
\hline Total & $\mathbf{0 . 4 0} \div \mathbf{1 . 5 0} \mathbf{k N} / \mathbf{m}^{2}$ \\
\hline
\end{tabular}

\begin{tabular}{ll}
\hline Wall & \\
\hline Steel members & $0.03 \div 0.08 \mathrm{kN} / \mathrm{m}^{2}$ \\
\hline External board - OSB & $0.05 \div 0.20 \mathrm{kN} / \mathrm{m}^{2}$ \\
\hline Internal board - GWB & $0.10 \div 0.20 \mathrm{kN} / \mathrm{m}^{2}$ \\
\hline Insulation & $0.02 \div 0.30 \mathrm{kN} / \mathrm{m}^{2}$ \\
\hline Internal finishing & $0.00 \div 0.20 \mathrm{kN} / \mathrm{m}^{2}$ \\
\hline External finishing & $0.10 \div 0.30 \mathrm{kN} / \mathrm{m}^{2}$ \\
\hline Total & $\mathbf{0 . 3 0} \div \mathbf{1 . 2 0} \mathbf{k N} / \mathbf{m}^{\mathbf{2}}$ \\
\hline
\end{tabular}

\subsection{Ground Motion}

In order to develop a non-linear dynamic seismic analysis, the seismic inputs have been selected in such a way that they could cover all the soil typologies classified by Eurocode 8 (CEN, [7]). In particular, Eurocode 8 provides five different soil types A, B, C, D, and E, but in this study only three spectra are adopted grouping the soil types B, C and E under one spectrum type. Therefore, 21 earthquake records have been selected from the ESD (European Strong-motion Database, www.isesd.cv.ic.ac.uk). For each soil type 7 accelerograms have been considered so that the shape of the average elastic response spectrum is close as much as possible to the shape of the corresponding Eurocode 8 elastic acceleration spectrum (Iervolino et al. [22]). As results, a total number of $504 \times 21$ $=10584$ cases have been obtained. The selected earthquakes include records from different European 
and Mediterranean regions. For these earthquakes the Richter magnitude range from 5.8 to 7.6. In order to match the design spectra the natural accelerograms have been scaled by the peak ground acceleration (PGA).

\subsection{Wall Response Modelling}

Each wall defined previously in the parametric study has been schematized as single degree of freedom structure, in which the hysteretic behaviour under horizontal loads is described by the model presented in Section 3.1. In particular, for the generic wall configuration the parameters defining the cyclic response have been set in such a way that the monotonic curve parameters give a function matching the relevant monotonic curve obtained in the parametric study, while the other parameters (UBC curve, LBC curve transition and strength degradation parameters) have been set equal to the value given in Table 4. This assumption implicates that in all the wall configurations examined in the parametric study the cyclic load produces the same effects observed in the tests carried out by Landolfo et al. [15].

In order to account the second order effects, a vertical load equal to the $100 \%$ of the mass has been considered. The viscous damping ratio has been set equal to $5 \%$, according to the experimental results obtained by Kawai et al. [4], Gad et al. [6] and Dubina [5]. The adopted procedure is the incremental dynamic analysis (IDA). Outputs of the analysis are the IDA curves, that are presented as adimentionalized elastic spectral acceleration $\left(S_{a, e} / g\right.$, intensity measure of the seismic record) vs. maximum required interstory drift angle $(d / h$, performance parameter). In particular, for obtaining a single IDA curve, which represents the response for a specific wall condition (wall geometry and materials, seismic weight and soil type), each accelerogram has been scaled in the range from 0.05 to 1.95 by considering 50 values. Therefore, a total number of $10584 \times 50=529200$ single non-linear dynamic analysis has been performed. Figure 5 shows typical IDA curves obtained in the present study by changing the accelerograms for a $2400 \mathrm{~mm}$ high and $1200 \mathrm{~mm}$ long wall, sheathed with GWB panels on both sides, having external screw spacing of $50 \mathrm{~mm}$ and a seismic weight of $15 \mathrm{kN} / \mathrm{m}$.

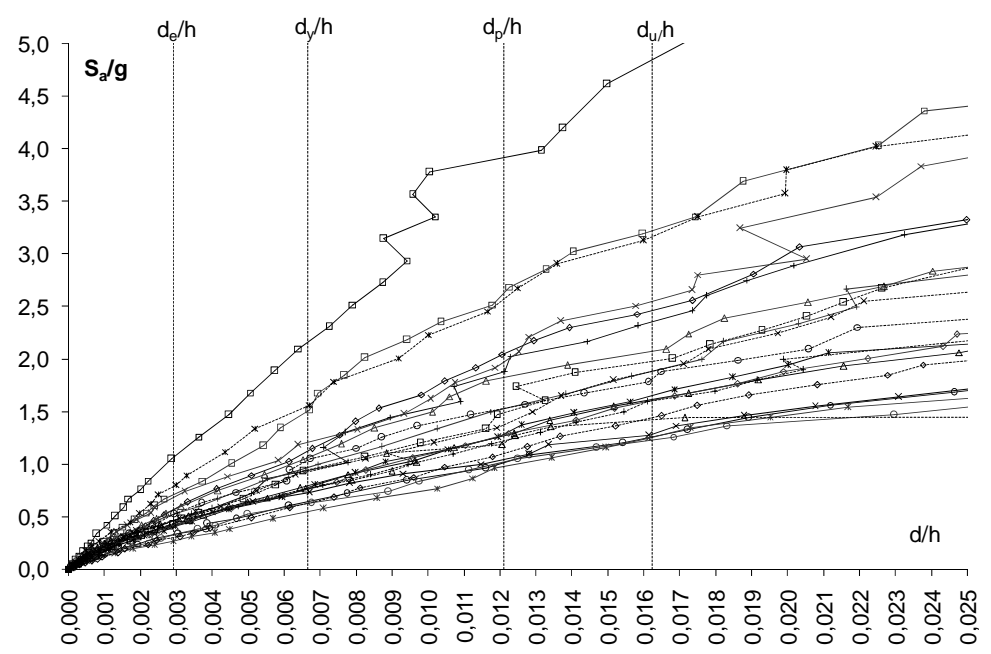

Figure 5. Typical IDA Curves 


\section{BEHAVIOUR FACTOR EVALUATION}

\subsection{General Assumptions}

Based on the results of performed dynamic analyses, the non-linear capacity of SCFS shear walls, in terms of behaviour factor, has been assessed. The numerical results have been interpreted by considering three different limit displacements on the generic response curve (Figure 6): the peak $\left(d_{p}\right)$ and ultimate $\left(d_{u}\right)$ displacements, as defined in Section 3.1, and the yielding displacement of the idealized bilinear curve $\left(d_{y}\right)$ created according to an equivalent energy elastic-plastic approach (Park [21]), following the recommendations given by Branston et al. [10].

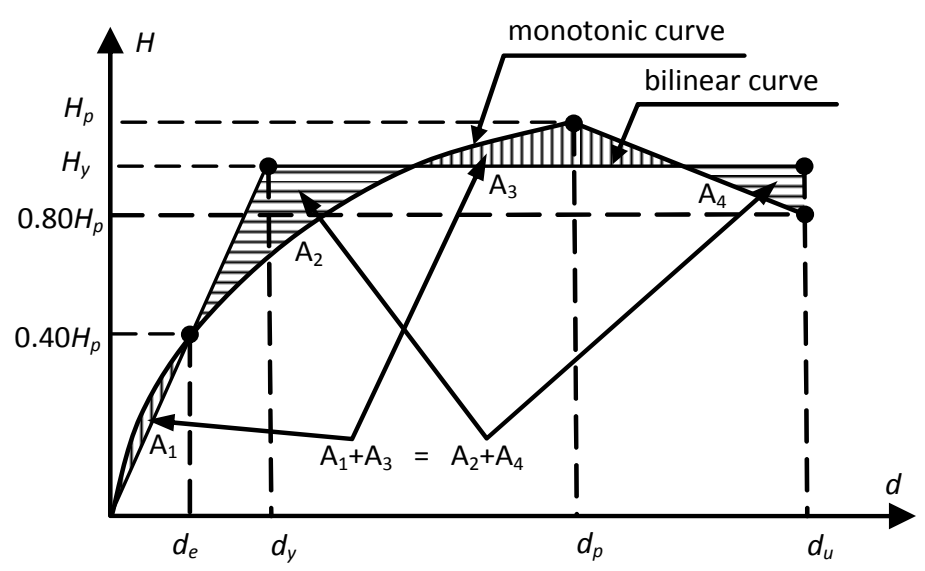

Figure 6. Monotonic Response Curve of a SCFS Shear Wall: Definition of the Idealized Bilinear Curve

For each IDA curve the seismic intensity measures $S_{a, y}, S_{a, p}$ and $S_{a, u}$ corresponding to the limit displacements $d_{y}, d_{p}$ and $d_{u}$, respectively, have been evaluated and these spectral accelerations have been used to define three different behaviour factors, as follows (Figure 7):

$q_{1}=S_{a, p} / S_{a, y}, \quad q_{2}=S_{a, u} / S_{a, p}, \quad q_{3}=S_{a, u} / S_{a, y}$

in which $q_{1}$ takes into account the overstrength, $q_{2}$ takes into account the ductility and $q_{3}=q_{1} q_{2}$ takes into account both overstrength and ductility.

In order to obtain an assessment of the behaviour factors $q_{1}, q_{2}$ and $q_{3}$ on the basis of significant IDA results, only the IDA curves representing realistic design conditions have been selected. The selection has been performed by comparing the displacement demand $\left(d_{D}\right)$ obtained for a given earthquake hazard level and different seismic intensity zones (i.e. peak ground acceleration on soil type A $\left(a_{g}\right)$ for a $10 \%$ probability of exceedance in 50 years equal to $0.15,0.25$ and $0.35 \mathrm{~g}$ for low, medium and high seismic intensity zone, respectively) with the relevant displacement capacity $\left(d_{C}\right)$ (i.e. conventional ultimate displacement, $d_{C}=d_{u}$ ). As result of this comparison, a performance coefficient $\left(p=d_{D} / d_{C}\right)$ has been defined and only the IDA curves for which $p$ satisfies specified target conditions (i.e. $0.5 \leq p \leq 1.0$ ) have been chosen. In particular, the selection of IDA curves has been performed by adopting two different approaches: "classical" and "multi-performance", in which the difference consists on the required performance objectives, as discussed in following Sections. 


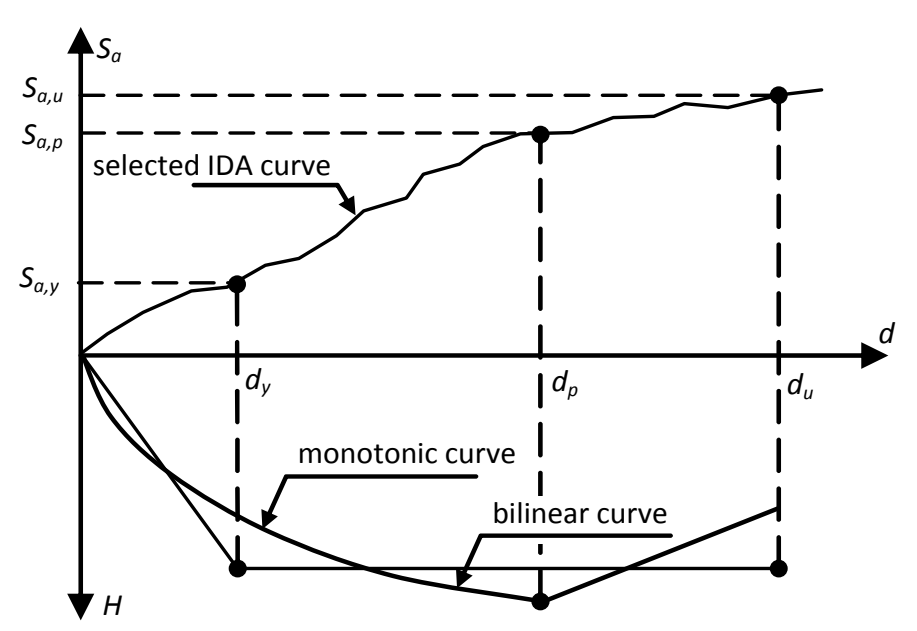

Figure 7. Definition of Behaviour Factors

\section{2 “Classic” Approach}

Nowadays, generally the seismic design according to current standards is performed by means of force-based approaches, in which in the case of the ultimate limit state the structural inelastic response and overstrength are taken into account by reducing the seismic force, that usually corresponds to an hazard seismic level equal to $10 \%$ probability of exceedance in 50 years $(10 \% / 50)$. Therefore, the evaluation of behaviour factors should be carried out on the basis of seismic demands required by records representative of 10\%/50 earthquakes, typically by relating this hazard level to the life safety structural performance. As result, these approaches allow significant structural damage under 10\%/50 earthquakes, by neglecting the seismic performance evaluation in the case of seismic events having lower probability of exceedance.

Following this approach, one required performance objective only has been selected, in which the displacement demand $\left(d_{D}\right)$ has been obtained under 10\%/50 earthquakes, with $a_{g}$ equal to $0.15 g$, $0.25 \mathrm{~g}$, and $0.35 \mathrm{~g}$ for low (LO), medium (ME) and high (HI) seismic intensity zone, respectively, and by adopting a displacement capacity corresponding to the ultimate displacement $\left(d_{C}=d_{u}\right)$. For each IDA curve for which the performance coefficient $p=d_{D} / d_{C}$ is in the range from 0.5 to 1.0 (Figure 8), the behaviour factors $q_{1}, q_{2}$ and $q_{3}$ have been evaluated.

The obtained average, standard deviation and coefficient of variation values of behaviour factors for $\mathrm{G}+\mathrm{G}, \mathrm{G}+\mathrm{O}$ and all walls $(\mathrm{G}+\mathrm{G}$ and $\mathrm{G}+\mathrm{O}$ together) are shown in Table 7. The results show that $q_{1}$ is about 2.4 for all types of wall configurations, $q_{2}$ is about 1.3, even if in case of walls sheathed with $\mathrm{G}+\mathrm{O}$ the value decreases to about 1.2 , and $q_{3}$ is about 3.0 for all walls, while for $\mathrm{G}+\mathrm{G}$ and $\mathrm{G}+\mathrm{O}$ configurations is about 3.2 and 2.9, respectively. As for as the dispersion of the data is concerned, the coefficient of variation ranges from 0.10 to 0.32 , which corresponds to moderately scattered results.

On the basis of results shown in Table 7 a behaviour factor $q=q_{3}=3.0$ is proposed for the "classic" seismic design under 10\%/50 earthquakes. 
Table 6. Performance Objective Matrix : "Classic” vs. "Multi-performance” Approach

\begin{tabular}{ccccc}
\cline { 2 - 4 } & & \multicolumn{3}{c}{ Performance levels } \\
\cline { 2 - 5 } & & IO & LS & CP \\
\hline \multirow{2}{*}{$\begin{array}{c}\text { Earthquake } \\
\text { hazard level }\end{array}$} & $50 \% 50$ & $\odot$ & & \\
\cline { 2 - 5 } & $10 \% 50$ & & $\odot$ & \\
\cline { 2 - 5 } & $2 \% 50$ & & & $O$ \\
\hline
\end{tabular}

- goal achieved by "classic" approach

O goal achieved by "multi-performance" approach

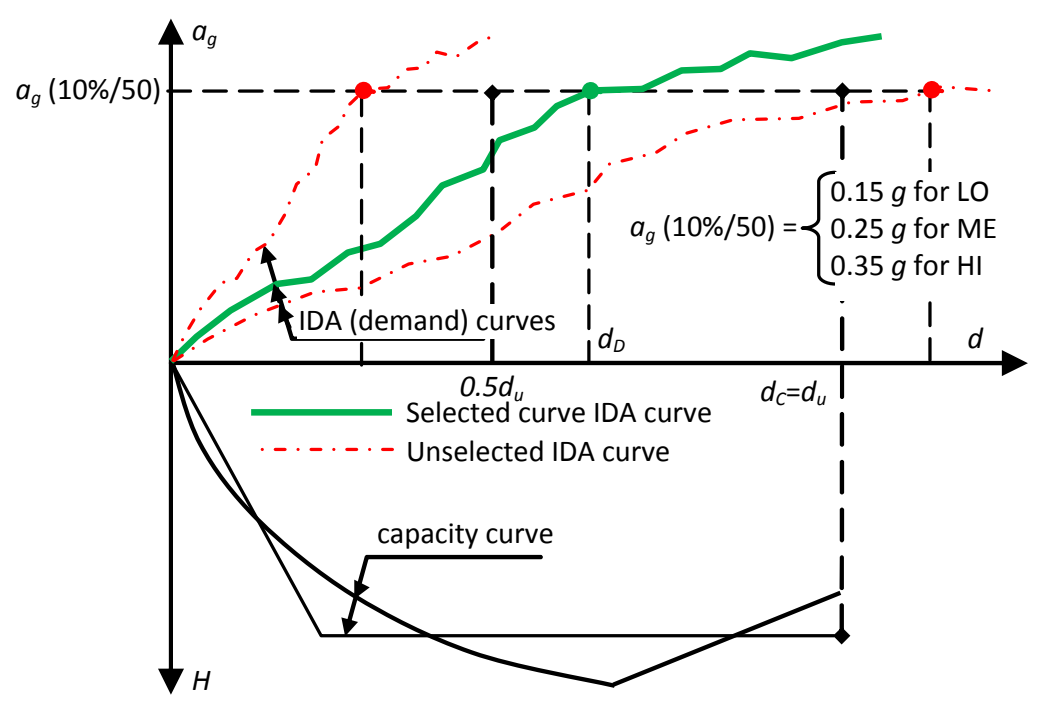

Figure 8. Selection of IDA Curves for the "Classic" Approach

Table 7. Behaviour Factors for the "Classic" Approach

\begin{tabular}{lllll}
\hline Wall configuration & & $q_{1}$ & $q_{2}$ & $q_{3}$ \\
\hline $\mathrm{G}+\mathrm{G}$ & Average & 2.37 & 1.32 & 3.16 \\
\cline { 2 - 5 } & St. Dev. & 0.53 & 0.20 & 1.02 \\
\cline { 2 - 5 } & C.o.V. & 0.22 & 0.15 & 0.32 \\
\hline $\mathrm{G}+\mathrm{O}$ & Average & 2.40 & 1.20 & 2.87 \\
\cline { 2 - 5 } & St. Dev. & 0.41 & 0.12 & 0.58 \\
\cline { 2 - 5 } & C.o.V. & 0.17 & 0.10 & 0.20 \\
\hline All types & Average & 2.38 & 1.27 & 3.04 \\
\cline { 2 - 5 }$(\mathrm{G}+\mathrm{G}$ and $\mathrm{G}+\mathrm{O})$ & St. Dev. & 0.49 & 0.19 & 0.88 \\
\cline { 2 - 5 } & C.o.V. & 0.20 & 0.15 & 0.29 \\
\hline
\end{tabular}

\section{3 “Multi-performance” Approach}

As attempt to overcome the limitations of as called "classic" approach, in this paper is proposed a methodology in which the different behaviour factors defined in Section 4.1 are related to different seismic performance levels, in such a way to obtain a "multi-performance" seismic design. The peculiarity of the proposed approach is to give the possibility to achieve an "enhanced objective" (FEMA 2010), consisting of the following goals (Table 5): (1) immediate occupancy (IO) performance level for earthquakes having $50 \%$ probability of exceedance in 50 years $(50 \% / 50)$, that is ground motions with mean return period of about 75 years or so called "frequent" earthquakes; (2) life safety (LS) performance level for earthquakes having $10 \%$ probability of exceedance in 50 years $(10 \% / 50)$, that is ground motions with mean return period of about 500 years or so called 
"rare" earthquakes; (3) collapse prevention (CP) performance level for earthquake with $2 \%$ probability of exceedance in 50 years $(2 \% / 50)$, that is ground motions with mean return period of about 2500 years or so called "very rare" earthquakes. Therefore, if the displacement capacities of the generic SCFS shear wall associated to the different performance levels are assumed as follows: yield displacement for IO $\left(d_{C, I O}=d_{y}\right)$, peak displacement for $\operatorname{LS}\left(d_{C, L S}=d_{p}\right)$ and ultimate displacement for $\mathrm{CP}\left(d_{C, C P}=d_{u}\right)$; then a seismic design which allows an adequate damage control for all selected earthquake hazard levels should be reached. In fact, for IO performance level the assumed displacement capacities correspond to the interstory drift limits $(d / h)$ ranging from $0.13 \%$ to $0.97 \%$, which are less than those (1.5\%) given by Dubina (2008). For LS and CP performance levels the assumed limits of $d / h$ range from $0.61 \%$ to $1.87 \%$ and from $0.73 \%$ to $2.44 \%$, respectively, which are generally more conservative values respect to those suggested by different Authors: 2.5\% for Dubina [5], 2.0\% for Kawai et al. [4], and from 1.91 to 2.23 for Blais [11].

The possibility of damage containment based on the assumed interstory drift limits is also supported by available experimental experiences, which confirm a damage of sheathing connections negligible for $d / h$ less than $1.0 \%$ (Figure 9a), which became tolerable for $d / h$ in the range $1.0 \%$ through $2.5 \%$ (Figure $9 b, c$ ).

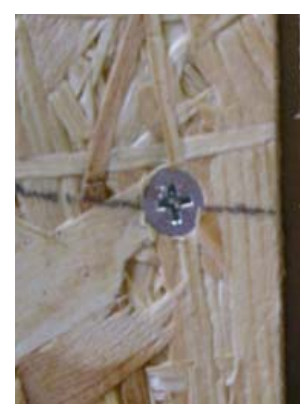

(a) $\mathrm{d} / \mathrm{h} \approx 0.6 \%$

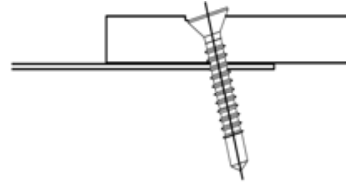

(a) Tilting in initial phase

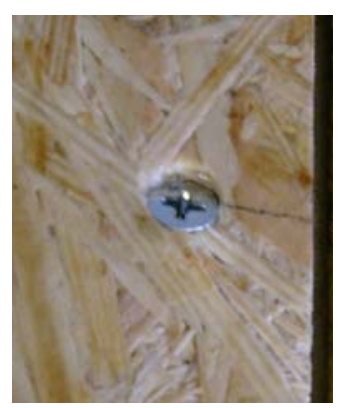

(b) $d / h \approx 1.4 \%$

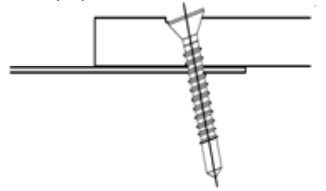

(b) Tilting in advanced phase and pull-trough in initial phase

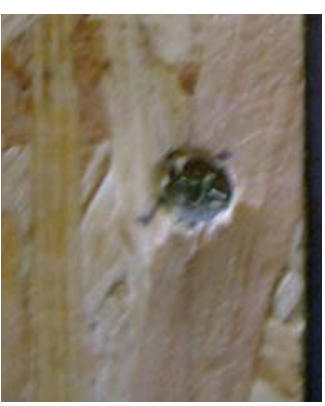

(c) $d / h \approx 2.0 \%$

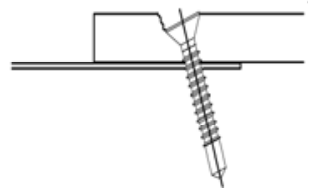

(c) Tilting and pull-trough in advanced phase

Figure 9. Experimental Observation of the Sheathing Fastener Damage during a Monotonic Test

According to this approach, for each selected seismic hazard level, three different seismic intensities have been assumed: $a_{g}$ equal to $0.06,0.10$, and $0.14 \mathrm{~g}$ for "frequent" earthquakes; 0.15 , 0.25 , and $0.35 \mathrm{~g}$ for "rare" earthquakes; and $0.23,0.38$, and $0.53 \mathrm{~g}$ for "very rare" earthquakes. Hence, in order to choose realistic cases, only IDA curves satisfying the following criterion (Figure 10) have been considered:

$$
\left(p_{I O}=d_{D, I O} / d_{C, I O} \leq 1\right) \cap\left(0.5 \leq p_{L S}=d_{D, L S} / d_{C, L S} \leq 1.0\right) \cap\left(p_{C P}=d_{D, C P} / d_{C, C P} \leq 1\right)
$$

The obtained average, standard deviation and coefficient of variation values of the behaviour factors $q_{1}, q_{2}$ and $q_{3}$ are shown in Table 7. From the obtained results, it can be observed that $q_{1}$ is about 2.2, 2.4 and 2.3 for walls sheathed with $\mathrm{G}+\mathrm{G}, \mathrm{G}+\mathrm{O}$ and all walls, respectively; $q_{2}$ is about 1.3 considering all types of wall configurations, while it is about 1.4 and 1.2 for $\mathrm{G}+\mathrm{G}$ and $\mathrm{G}+\mathrm{O}$ 
configurations, respectively; $q_{3}$ is about $3.1,2.9$ and 3.0 for walls sheathed with $\mathrm{G}+\mathrm{G}, \mathrm{G}+\mathrm{O}$ and all wall typologies. The results in terms of dispersion are very similar to those observed in case of the "classic" approach, with a coefficient of variation in the range from 0.10 to 0.27 .

According to the proposed multi-performance approach and by considering the obtained results, a behaviour factor $q=q_{1}=2.0$ is proposed in the case of "rare" $(10 \% / 50)$ earthquakes, while its value should be assumed equal to $q=q_{3}=3.0$ for "very rare" $(2 \% / 50)$ earthquakes.

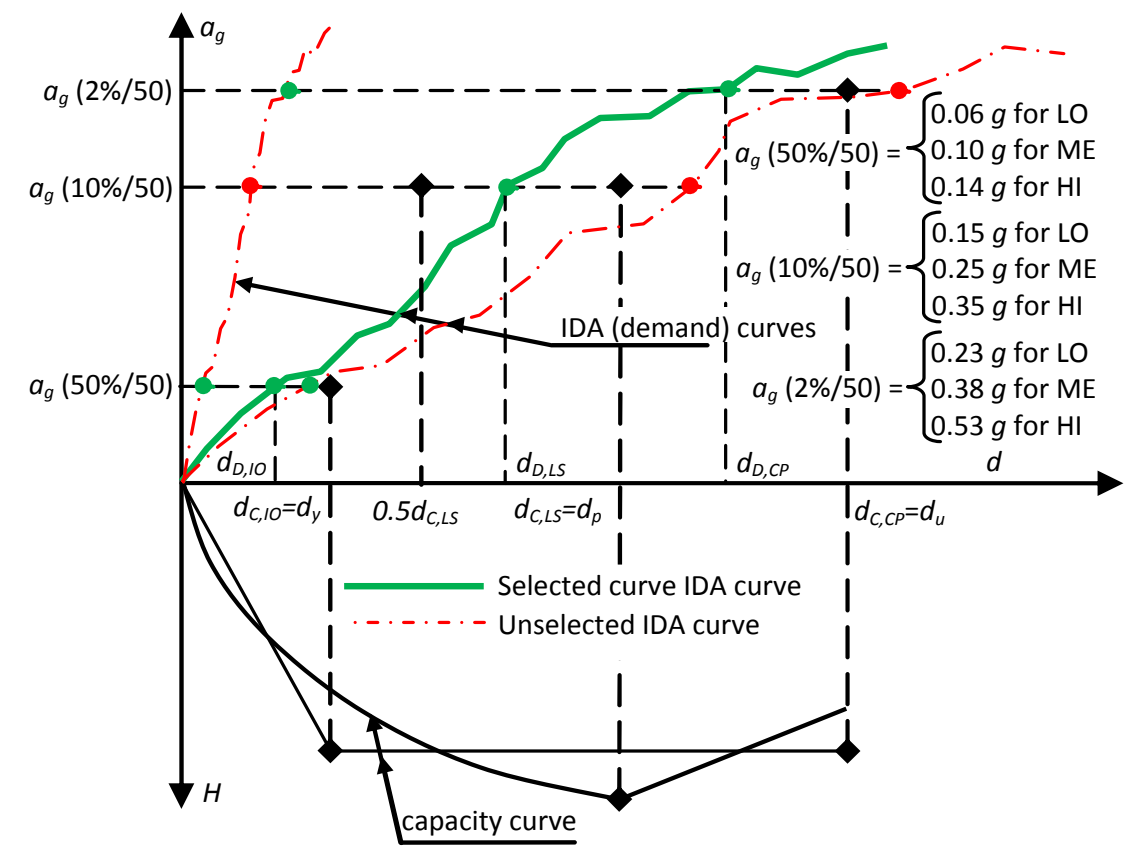

Figure 10. Selection of IDA Curves for the "Multi-performance" Approach

Table 8. Behaviour Factors for the "Multi-performance" Approach

\begin{tabular}{|c|c|c|c|c|}
\hline $\begin{array}{l}\text { Wall } \\
\text { configuration }\end{array}$ & & $q_{1}$ & $q_{2}$ & $q_{3}$ \\
\hline \multirow[t]{3}{*}{$\mathrm{G}+\mathrm{G}$} & Average & 2.23 & 1.35 & 3.05 \\
\hline & St. Dev. & 0.44 & 0.17 & 0.83 \\
\hline & C.o.V. & 0.20 & 0.13 & 0.27 \\
\hline \multirow[t]{3}{*}{$\mathrm{G}+\mathrm{O}$} & Average & 2.35 & 1.23 & 2.88 \\
\hline & St. Dev. & 0.40 & 0.12 & 0.57 \\
\hline & C.o.V. & 0.17 & 0.10 & 0.20 \\
\hline \multirow{3}{*}{$\begin{array}{l}\text { All types } \\
(\mathrm{G}+\mathrm{G} \text { and } \mathrm{G}+\mathrm{O})\end{array}$} & Average & 2.29 & 1.29 & 2.96 \\
\hline & St. Dev. & 0.43 & 0.16 & 0.71 \\
\hline & C.o.V. & 0.19 & 0.12 & 0.24 \\
\hline
\end{tabular}

\subsection{Comparison with Literature Results and Code Prescriptions}

Considering the behaviour factors defined on the basis of non-linear dynamic analysis results using "classic" and "multi-performance" approaches, they range between 2.2 and 2.4 for $q_{1}$ (overstrength) between 1.2 and 1.4 for $q_{2}$ (ductility) and from 2.9 to 3.2 for $q_{3}$ (both overstrength and ductility).

The values of overstrength related factor $\left(q_{1}\right)$ achieved in this study are very similar to those $\left(q_{1}=2.2 \div 2.6\right)$ proposed by Fülöp and Dubina [1], while they are larger than the corresponding result $\left(R_{o}=1.7\right)$ given by Boudreault et al. [3]. For the values of the ductility related factor $\left(q_{2}\right)$, they are 
slightly smaller than the results $\left(q_{2}=1.4 \div 1.6\right)$ obtained by Fülöp and Dubina [2] and quite smaller than the factor $\left(R_{d}=2.5\right)$ proposed by Boudreault et al. [3]. As consequence, the results obtained in terms of global behaviour $\left(q_{3}\right)$, which represents the product of $q_{1}$ and $q_{2}$ are smaller than those achieved by Fülöp \& Dubina [2] $\left(q_{3}=3.6 \div 3.7\right)$ and Boudreault et al. [3] $\left(R_{o} \times R_{d}=4.3\right)$. Finally, considering the global behaviour factor $\left(q_{3}\right)$, the comparison with the prescriptions of applicable Codes shows that the value proposed in this paper is in the very large range $\left(q_{3}=R=2 \div 6.5\right)$ of those given by ASCE/SEI 7-10 [13] and FEMA P-750 [8].

\section{CONCLUSIONS}

In the last years a large number of research teams have been involved in the evaluation of seismic capacity of SCFS structures and seismic design parameters as behaviour factors and interstory drift limits so as dynamic characteristics as vibration periods and damping ratios have been evaluated. In this paper the results of extensive parametric dynamic analyses on sheathed cold-formed steel (SCFS) shear walls, performed by a presented cyclic model able to predict the non linear force deflection response, have been presented. Based on the results of the analyses the seismic performance of SCFS shear walls, in terms of behaviour factors has been assessed. In particular, three behaviour factors related to overstrength $\left(q_{1}=2\right)$, ductility $\left(q_{2}=1.5\right)$ and both overstrength and ductility $\left(q_{3}=3\right)$ have been defined.

In addition, two different seismic design approaches have been proposed. For the first approach, named "classic", in which 10\%/50 hazard level is related to the life safety structural performance, a behaviour factor $q=q_{3}=3$ is proposed to be used. For the second approach, named "multi-performance", different behaviour factors are related to different seismic performance levels, in such a way to achieve an "enhanced objective" by allowing an effective damage control. Under this assumption, a behaviour factor equal to $q=q_{2}=2$ is proposed for $10 \% / 50$ hazard level, which is related to live safety structural performance; while a behaviour factor of $q=q_{3}=3$ should be used for $2 \% / 50$ hazard level, which correspond to collapse prevention structural performance.

\section{REFERENCES}

[1] Fülöp, L.A. and Dubina, D., "Performance of Wall-stud Cold-formed Shear Panels under Monotonic and Cyclic Loading Part I: Experimental Research", Thin Walled Structures, Elsevier, 2004, Vol. 42, No. 2, pp. 321-338.

[2] Fülöp, L.A. and Dubina, D., "Performance of Wall-stud Cold-formed Shear Panels under Monotonic and Cyclic Loading Part II: Numerical Modelling and Performance Analysis", Thin Walled Structures, Elsevier, 2004, Vol. 42, No. 2, pp. 339-349.

[3] Boudreault, F.A., Blais, C. and Rogers, C.A., "Seismic Force Modification Factors for Light-gauge Steel-frame - Wood Structural Panel Shear Walls", Canadian Journal of Civil Engineering. 2007, Vol. 3, No. 1. pp. 56-65.

[4] Kawai, Y., Kanno, R., Uno, N. and Sakumoto, Y., "Seismic Resistance and Design of Steel Framed-houses, Nippon Steel Technical Report, No. 79, 1999.

[5] Dubina, D., "Behaviour and Performance of Cold-formed Steel-framed Houses under Seismic Action", Journal of Constructional Steel Research, 2008, Vol. 64, pp. 896-913.

[6] Gad, E.F., Duffield, C.F., Hutchinson, G.L., Mansell, D.S. and Stark, G., "Lateral Performance of Cold-formed Steel-framed Domestic Structures", Engineering Structures, Elsevier, 1999, Vol. 21, pp. 83-95. 
[7] CEN. EN 1998-1 - Eurocode 8: Design of Structures for Earthquake Resistance - Part 1: General Rules, Seismic Actions and Rules for Buildings, European Committee for Standardization, Bruxelles, 2004.

[8] FEMA P-750, NEHRP Recommended Provision for Seismic Provisions for New Buildings and Other Structures, Federal Emergency Management Agency, Washington, D.C., 2010.

[9] NRCC. National Building Code of Canada (NBCC), National Research Council Canada, Ottawa, Ontario, 2005.

[10] Branston, A.E., Chen, C.Y., Boudreault, F.A. and Rogers, C.A., "Testing of Light-gauge Steel-frame - Wood Structural Panel Shear Walls", Canadian Journal of Civil Engineering, 2006, Vol. 33, No. 5, pp. 561-572.

[11] Blais, C., "Testing and Analysis of Light Gauge Steel Frame / 9mm OSB Wood Panel Shear Walls, Master's Thesis, Dept. of Civil Engineering and Applied Mechanics, McGill University, Montreal, Canada, 2006.

[12] Rokas, D., "Testing and Evaluation of Light Gauge Steel Frame / $9.5 \mathrm{~mm}$ CSP Wood Panel Shear Walls, Master's Thesis, Dept. of Civil Engineering and Applied Mechanics, McGill University, Montreal, Canada, 2006.

[13] ASCE/SEI 7-10, "Minimum Design Loads for Buildings and Other Structures", American Society of Civil Engineers, Reston, 2010.

[14] Landolfo, R., Fiorino, L. and Iuorio, O., "A Specific Procedure for Seismic Design of Cold-Formed Steel Housing", Advanced Steel Construction, 2010, Vol. 6, No.1, pp. 603-618.

[15] Landolfo, R., Fiorino, L. and Della Corte, G., "Seismic Behaviour of Sheathed Cold-formed Structures: Physical Tests", Journal of Structural Engineering, 2006, Vol. 132, No. 4, pp. 570-581.

[16] Iuorio, O., "Design Procedures for Cold Formed Steel Housing in Seismic Area", PhD Thesis, University of G. D'Annunzio, Chieti, Pescara, Italy, 2009.

[17] Fiorino, L., Iuorio, O. and Landolfo, R., "Sheathed Cold-formed Steel Housing : A Seismic Design Procedure", Thin- Walled Structures, 2009, Vol. 47, No. 8-9, pp. 919-930.

[18] Simpson Strong-Tie Company, 2007, www.strongtie.com.

[19] Hilti. North America Product Technical Guide, 2005.

[20] Della Corte, G., Landolfo, R., and Fiorino, L., "Seismic Behaviour of Sheathed Cold Formed Structures : Numerical Study", Journal of Structural Engineering, ASCE, 2006, Vol.132, No. 4, pp. 558-69.

[21] Park, R., "Evaluation of Ductility of Structures and Structural Assemblages from Laboratory Testing", Bulletin of the New Zealand National Society for Earthquake Engineering, 1989, Vol. 22, No. 3, pp. 155-166.

[22] Iervolino, I., Maddaloni, G. and Cosenza, E., "Unscaled Real Record Sets Compliant with Eurocode 8, First European Conference on Earthquake Engineering and Seismology, Geneva, Switzerland, 2006. 